\title{
Metodologias Ativas de Aprendizagem: Desafios dos Docentes de Duas Faculdades de Medicina do Rio Grande do Sul, Brasil
}

\author{
Active Learning Methodologies: Challenges for Professors of Two \\ Medical Schools in Rio Grande do Sul, Brazil
}

\author{
Maríndia Biffi ${ }^{I}$ \\ Margarita Silva Diercks ${ }^{I I} \mathbb{D}$ \\ Bárbara Cristina Barreiros ${ }^{I I I}$ (ID \\ Ananyr Porto Fajardo ${ }^{I I}$ D
}

\section{PALAVRAS-CHAVE}

- Estudos de Avaliação como Assunto.

- Aprendizagem Ativa.

- Educação Médica.

- Saúde Coletiva.

- Faculdades de Medicina.
${ }^{\mathrm{I}}$ Universidade Federal da Fronteira Sul, Passo Fundo, Rio Grande do Sul, Brasil.

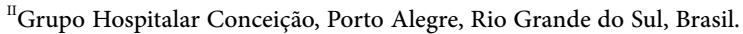

${ }^{\text {III }}$ Secretaria Municipal de Saúde, São Bernardo do Campo, São Paulo, Brasil 


\section{KEYWORDS}

- Evaluation Studies as Topic.

- Active learning.

- Medical Education.

- Public Health.

- Schools Medical.

\section{ABSTRACT}

Introduction: The 2014 curricular guidelines for medical courses in Brazil aim to train humanist, critic, reflexive and ethic general practitioners, able to work at different levels of health care, primarily based within the National Unified Health System scope. To achieve this goal, higher education institutions must adopt educational technologies such as active learning methodologies, which encourage students to seek and build their own knowledge. This study aims to identify and analyze the challenges faced by Public Health teachers from two medical courses in the state of Rio Grande do Sul, Brazil in the use of Active Learning Methodologies. Method: The study was conducted as a qualitative research with a comparative case study approach, and the subjects comprised teachers of the abovementioned discipline in both universities. The information was collected through a sociodemographic questionnaire, semi-structured interviews, and semi-directed observation. The findings were assessed using thematic analysis and the questionnaire data were tabulated to assess its frequency. Result: The main findings were the understanding, on the part of the teachers, of the relevance of active methodologies in the teaching pedagogical processes, the difficulty of including them due to the lack of preparation, and the understanding of the need for the active teaching methodologies to guide the pedagogical project. Conclusion: It is concluded that the universities should be encouraged to build a continuing education project for the teaching staff in which these methodologies are assumed as the main point in the teaching practice, also contributing to reflect on the established training model, as well as to rethink the organization of the political pedagogical project of medical courses.

Recebido em 15/1/20

Aceito em 31/8/20

\section{INTRODUÇÃO}

Em junho de 2014, o Conselho Nacional de Educação instituiu novas Diretrizes Curriculares Nacionais do Curso de Graduação em Medicina (DCN-CGM), as quais constituem orientações obrigatórias para a elaboração dos currículos adotados por todas as faculdades de Medicina do país.

Conforme as DCN-CGM ${ }^{1}$, o graduando de Medicina deverá ter uma formação geral, humanista, crítica, reflexiva e ética, com capacidade para atuar nos diferentes níveis de atenção à saúde, com responsabilidade social, compromisso com a defesa da cidadania, da dignidade humana, da saúde integral do ser humano e tendo como transversalidade em sua prática a determinação social do processo de saúde e doença.

Para atingir esse objetivo, sugere-se a utilização de metodologias ativas de aprendizagem (MAP) como principal referencial do processo educativo dos cursos de Medicina ${ }^{2}$. As MAP são consideradas tecnologias educacionais leve-duras que proporcionam engajamento dos educandos no processo de aprendizagem e que favorecem o desenvolvimento de capacidade crítica e reflexiva relacionadas à sua prática profissional ${ }^{3,4}$. É um processo sustentado nas interações sociais que possibilita a apropriação e construção compartilhada do conhecimento. Assim, as novas formulações e/ou compreensões dos objetivos de estudo não são adquiridas somente pela transmissão de conteúdos, mas também são produzidas a partir do significado atribuído pelo estudante, condicionado por suas experiências, seus contextos e suas condições de vida ${ }^{5}$. As MAP são capazes de promover o desenvolvimento do estudante na direção da formação de um profissional competente (apropriado de conteúdos, habilidades e atitudes esperados), bem como comprometido com a sociedade em que vive e atua ${ }^{5}$.

A aprendizagem ativa é ancorada na pedagogia crítica e com múltiplos métodos possíveis, como estudo de caso, metodologia da problematização com o arco de Maguerez, peer education, aprendizagem baseada em equipes, aprendizagem baseada em projetos e aprendizagem baseada em problemas (o método mais amplamente utilizado nos cursos de Medicina) ${ }^{6}$. Com esses métodos mais complexos, as estratégias didáticas ativas de ensino e aprendizagem são recursos efetivos utilizados pelos docentes no cotidiano de aprendizado do aluno. Essas estratégias têm dois componentes: as dinâmicas ativas de ensino e aprendizagem (DAEA) e as ações para o ensino ativo (AEA) ${ }^{7}$.

As DAEA são técnicas utilizadas pelo docente para o ensino; já as AEA correspondem a intervenções, posturas e atitudes tomadas pelo docente que potencializam o ensino ativo ${ }^{8}$. As DAEA podem ser implementadas em qualquer ambiente de sala de aula. Gleason et al. ${ }^{8}$ apontam as seguintes DAEA: questionamento socrático, debates, aquário, dramatizações - role-plays, apresentações estudantis, jogos, dispositivos de pesquisa/sistemas de resposta de audiência, entre outras.

Nas MAP, o docente deve abandonar a perspectiva do mestre, transmissor de conhecimento, e assumir um papel de facilitador do processo de ensino, pois o professor assume uma posição muito mais de cooperação do que de detentor da verdade ${ }^{6}$, sendo seu principal papel estimular o pensamento crítico e o autoaprendizado dos estudantes.

Freitas et al. ${ }^{9}$ afirmam que o professor necessita pensar sobre o processo educacional para estruturá-lo; contudo, em geral, esses profissionais ingressam na carreira de educadores sem capacitação pedagógica para a atuação docente, apesar de terem habilidade em sua especialidade. Diante disso, a ação docente tem sido fundamentada na experiência vivenciada em seu processo de formação, espelhando-se em seus próprios professores, que orientavam suas aulas por métodos tradicionais de ensino ${ }^{10}$.

As metodologias ativas trazem benefícios diretos ao educando, pois possibilitam o desenvolvimento de sua autonomia, formando um profissional criativo, reflexivo, independente e capaz de empregar os conhecimentos adquiridos de forma holística, minimizando a ocorrência de uma educação fragmentada ${ }^{7,11,12}$. Além disso, elas ensejam uma formação médica contemporânea, voltada para o futuro das compreensões e intervenções do profissional médico, em um mundo em que as mudanças oriundas das ininterruptas descobertas desafiam um conjunto de competências, com um profissional atualizado e resolutivo ${ }^{13}$.

Para que isso ocorra, o docente tem que se tornar cada vez mais um gestor e orientador de caminhos coletivos e individuais ${ }^{14}$. Porém, esse

REVISTA BRASILEIRA DE EDUCAÇ̃̃o MÉDICA

2 44 (4) : e145; 2020 
processo é permeado por dificuldades, pois alguns professores não têm confiança para implementar essas tecnologias educacionais ou consideram arriscado compartilhar o controle da aula com os alunos, havendo também relatos referentes à falta de tempo para organização das atividades ${ }^{8,10,15,16}$.

No entanto, um empecilho para aplicar metodologias ativas é a exigência de investimentos e uma reforma curricular que pode ser radical no que se refere ao processo pedagógico. A implantação dessa arquitetura curricular não se dá de forma abrupta e sem amplo planejamento das instituições de ensino superior ${ }^{6,7}$, que adquirem papel fundamental na sustentação de qualquer modelo curricular inovador implantado. No currículo em questão, é importante que os docentes se dediquem preferencialmente de forma integral à instituição e que sejam preparados para atuar de forma participativa na formação acadêmica ${ }^{6}$.

Destaca-se a importância do docente manter-se em permanente formação e acompanhando os movimentos, as inovações e o desenvolvimento do projeto político-pedagógico (PPP); porém, seu desconhecimento acerca do PPP dificulta essa ação ${ }^{17}$. Daí surge a necessidade de qualificar educadores para que possam ler a realidade $\mathrm{e}$ contribuir para o conhecimento e a aprendizagem do discente ${ }^{18}$.

Este estudo foi desenvolvido em duas universidades do interior do Rio Grande do Sul: universidade 1 (U1), criada em 1970, e universidade 2 (U2), criada em 2009. Ambas são organizadas de forma semestral, com ingressos na U1 por prova de vestibular e na U2 por meio do Sistema de Seleção Unificada (SiSU). Por ser mais antiga, a U1 readaptou seu PPP conforme as DCN-CGM de 2014, quando as MAP foram acrescentadas como metodologias de ensino. Já a U2 foi criada tendo como base as DCN-CGM de 2014, e, portanto, incluíram-se as MAP em seu PPP.

Ambas as universidades incluem a disciplina de Saúde Coletiva em todos os semestres da graduação até o internato, e as ementas das duas instituições são muito semelhantes ${ }^{19,20}$.

Esta pesquisa teve como objetivos identificar e analisar as possibilidades e dificuldades com as MAP dos docentes da disciplina de Saúde Coletiva de dois cursos de Medicina do interior do Rio Grande do Sul. Os objetivos específicos foram descrever o perfil sociodemográfico dos docentes envolvidos, relatar suas vivências e concepções sobre a aprendizagem ativa, bem como analisar as diferenças entre elas e as dificuldades enfrentadas para implementar as MAP pelos participantes.

\section{MÉTODO}

Trata-se de pesquisa qualitativa do tipo estudo de caso comparativo ${ }^{21}$.

A população foi composta por docentes da disciplina de Saúde Coletiva do curso de Medicina da U1 e U2. Adotaram-se os seguintes critérios de inclusão: ser docente efetivo da disciplina Saúde Coletiva das duas universidades e ter, em março de 2018, no mínimo um ano de experiência na docência. Excluíram-se aqueles que estavam em licença-saúde, licença para estudo, licença-maternidade ou férias no período da coleta dos dados, os que ministravam apenas aulas práticas, os que se recusaram a participar de alguma das etapas da pesquisa e aqueles que não tiveram interesse em participar ou não responderam a pelo menos dois convites para fazer parte do estudo. De um total de 23 docentes das duas universidades, nove compuseram a amostra final deste estudo, sendo a participação voluntária. Entre as seis mulheres e os quatro homens que não aceitaram os convites ou não responderam a eles, havia seis médicos, três farmacêuticos e um enfermeiro; cinco eram especialistas; três, mestres; e dois, doutores.
Consideramos que houve saturação das informações, resultando em aprofundamento do tema proposto, grande abrangência de categorias empíricas e analíticas, assim como diversidade no processo de compreensão das percepções trazidas pelos preceptores dos dois grupos estudados ${ }^{22}$.

As informações foram coletadas por meio de instrumentos utilizados em diferentes etapas:

- Questionário estruturado autoaplicável para caracterização sociodemográfica, percurso profissional e processo formativo dos participantes, enviado por e-mail com o Termo de Consentimento Livre e Esclarecido (TCLE) para todos os potenciais sujeitos da pesquisa. Depois de concordar em participar da pesquisa e assinar TCLE, o docente deveria preencher o questionário.

- Observação semidirigida de aulas dos docentes participantes deste estudo, objetivando descrever a vivência dos docentes com as MAP.

- Entrevista individual semiestruturada com perguntas orientadoras relacionadas aos objetivos do estudo, que ocorreu após a observação das aulas. Todas as entrevistas foram gravadas e posteriormente transcritas na sua íntegra. As entrevistas foram realizadas pela pesquisadora principal, presencialmente, respeitando sigilo e privacidade.

Criaram-se dois grupos diferentes para a comparação dos resultados: o grupo A corresponde aos docentes da U1 e receberam a letra "A", assim como os docentes da U2 receberam a letra "B", todos de forma aleatória. As informações registradas nos questionários estruturados autoaplicáveis foram tabuladas para exame de sua frequência. As observações semidirigidas foram registradas, lidas e categorizadas para elencar os principais temas. Esses temas foram retomados nas entrevistas semiestruturadas com o objetivo de identificar as contradições entre teoria e prática.

As entrevistas semiestruturadas individuais, após transcrição literal, foram lidas e sumarizadas atendendo aos critérios de exaustividade, representatividade e pertinência do conteúdo das respostas obtidas ${ }^{22} . \mathrm{Na}$ exploração do material, examinou-se o produto individual, alcançandose categorias de expressões representativas do tema e de sua abordagem. Nesse momento, identificaram-se 33 categorias empíricas, que foram agrupadas em três categorias. Das categorias resultantes do agrupamento, selecionaram-se três categorias de análise, que foram exploradas a partir dos conceitos de referência das MAP, conforme mostra o Quadro 1.

O estudo seguiu a Resolução $n^{\circ} 466 / 2012^{23}$ e foi aprovado pelo Comitê de Ética do Grupo Hospitalar Conceição mediante o Parecer $n^{\circ}$ 16-119, com Certificado de Apresentação para Apreciação Ética (CAAE) $n^{\circ}$ 89303118.3.0000.5530.

Neste artigo, serão descritas duas categorias de análise: conhecimento e vivências das MAP por parte dos docentes e possibilidades e dificuldades da prática profissional dos docentes com as MAP.

\section{RESULTADOS E DISCUSSÃO}

Caracterização dos sujeitos

As informações oriundas do questionário sociodemográfico estão sistematizadas na Quadro 2. A faixa etária predominante é dos 37 aos 56

REVISTA BRASILEIRA DE EDUCAÇÃO MÉDICA

3 44 (4) : e145; 2020 


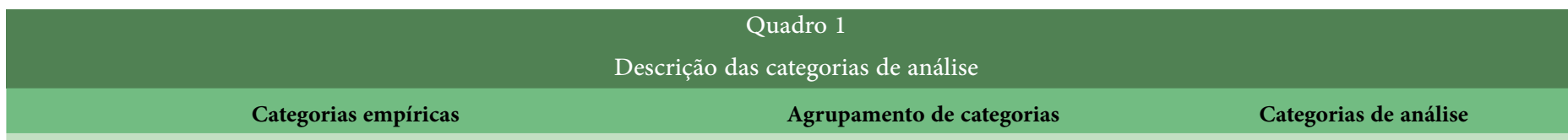

\section{Educação popular}

Aprendizagem baseada em problemas (Problem-based learning - PBL)

Peer education (educação entre pares)

Aprendizado baseado em projetos (Project-based learning - PjBL)

Tipos de metodologias ativas

Conhecimento e vivências das MAP por parte dos docentes

Aprendizagem baseada em equipes (Team-based learning - TBL)

MAP - Políticas institucionais

MAP - Novos processos pedagógicos

MAP - Discente

MAP - Capacitação docente

MAP - Docente

MAP - Dificuldade de avaliação discente

MAP - Potencialidades

MAP - Campo prático

MAP - Prática docente

MAP - Processo histórico das macro

MAP - Processo histórico das micro

Dificuldade de tempo para organização das aulas

Dificuldade estrutural (material didático, estrutura, equipamentos,

internet)

Dificuldades financeiras docentes

Dificuldades com os discentes

Dificuldade de formação docente

Ferramentas didáticas + telemedicina

Prática profissional atual

Trajetória profissional

Possibilidades e dificuldades da prática profissional dos docentes com as metodologias ativas de aprendizagem

Modelo histórico do ensino médico

Modelo de formação docente

Mudanças do aluno

Mudança do perfil docente

Processo pedagógico - atividades pedagógicas na docência

Preparação das aulas dos docentes

Realização profissional

Realização do aluno

Fonte: Elaborado pelas autoras, 2019.

\begin{tabular}{|c|c|c|c|c|c|c|c|c|c|}
\hline & & & & $\begin{array}{r}\mathrm{Q} \\
\text { aracterizaçã }\end{array}$ & $\begin{array}{l}\text { dro } 2 \\
\text { dos particip }\end{array}$ & ates & & & \\
\hline $\begin{array}{c}\text { A -U1 } \\
\text { B -U2 } \\
\text { Idade / sexo }\end{array}$ & Formação & Ano & Mestrado & Doutorado & $\begin{array}{l}\text { Atuação - } \\
\text { maior CH }\end{array}$ & Forma de ingresso & $\begin{array}{c}\text { Faixa salarial } \\
\text { - salários } \\
\text { mínimos }\end{array}$ & $\begin{array}{c}\mathrm{CH}- \\
\text { horas } \\
\text { semanais }\end{array}$ & $\begin{array}{l}\text { Ano de } \\
\text { ingresso }\end{array}$ \\
\hline $\begin{array}{c}\text { A1 / } 56 \\
\text { Feminino }\end{array}$ & Enfermagem & 1998 & $\begin{array}{l}\text { Gestão em saúde } \\
\text { Em andamento }\end{array}$ & & Docência & Contrato & Entre 3 e 6 & 23 & 2010 \\
\hline $\begin{array}{c}\text { A2/ } 40 \\
\text { Feminino }\end{array}$ & Odontologia & 2002 & $\begin{array}{c}\text { Saúde Coletiva } \\
\text { Concluído }\end{array}$ & $\begin{array}{l}\text { Saúde } \\
\text { Coletiva }\end{array}$ & Docência & Seleção & Entre 3 e 6 & 22 & 2010 \\
\hline $\begin{array}{c}\text { A3 / } 38 \\
\text { Feminino }\end{array}$ & Fisioterapia & 2004 & $\begin{array}{l}\text { Epidemiologia } \\
\text { Concluído }\end{array}$ & & Docência & Concurso - privada & Entre 3 e 6 & 26 & 2015 \\
\hline $\begin{array}{c}\text { A4 / } 40 \\
\text { Feminino }\end{array}$ & Medicina & 2003 & $\begin{array}{c}\text { Envelhecimento } \\
\text { Humano } \\
\text { Concluído }\end{array}$ & & Docência & Concurso público & Entre 3 e 6 & 20 & 2009 \\
\hline $\begin{array}{c}\text { B1 / } 52 \\
\text { Feminino }\end{array}$ & Filosofia & 1999 & $\begin{array}{c}\text { Educação - ênfase na } \\
\text { Saúde } \\
\text { Concluído }\end{array}$ & $\begin{array}{l}\text { Educação } \\
\text { - ênfase na } \\
\text { Saúde }\end{array}$ & Docência & Concurso público & Entre 6 e 9 & $40 \mathrm{DE}$ & 2013 \\
\hline
\end{tabular}




\begin{tabular}{|c|c|c|c|c|c|c|c|c|c|}
\hline & & & & Qon & $\begin{array}{l}\text { dro } 2 \\
\text { nuação. }\end{array}$ & & & & \\
\hline $\begin{array}{c}\text { A -U1 } \\
\text { B -U2 } \\
\text { Idade / sexo }\end{array}$ & Formação & Ano & Mestrado & Doutorado & $\begin{array}{l}\text { Atuação - } \\
\text { maior CH }\end{array}$ & Forma de ingresso & $\begin{array}{c}\text { Faixa salarial } \\
\text { - salários } \\
\text { mínimos }\end{array}$ & $\begin{array}{c}\mathrm{CH}- \\
\text { horas } \\
\text { semanais }\end{array}$ & $\begin{array}{l}\text { Ano de } \\
\text { ingresso }\end{array}$ \\
\hline $\begin{array}{c}\text { B2 / } 43 \\
\text { Masculino }\end{array}$ & Medicina & 2004 & $\begin{array}{c}\text { Envelhecimento } \\
\text { Humano } \\
\text { Em andamento }\end{array}$ & & Assistência & Concurso público & Entre 3 e 6 & 20 & 2016 \\
\hline $\begin{array}{c}\text { B3 / } 36 \\
\text { Masculino }\end{array}$ & Medicina & 2009 & $\begin{array}{c}\text { Mestrado Profissional } \\
\text { em MFC } \\
\text { Em andamento }\end{array}$ & & Assistência & Concurso público & Entre 6 e 9 & 20 & 2017 \\
\hline $\begin{array}{c}\text { B4 / } 40 \\
\text { Feminino }\end{array}$ & Medicina & 2005 & $\begin{array}{c}\text { Envelhecimento } \\
\text { Humano } \\
\text { Concluído }\end{array}$ & & Docência & Concurso público & Entre 6 e 9 & 40 & 2017 \\
\hline $\begin{array}{c}\text { B5/ } 41 \\
\text { Masculino }\end{array}$ & Medicina & 2002 & $\begin{array}{c}\text { Epidemiologia } \\
\text { Concluído }\end{array}$ & & Gestão & Seleção específica & Mais de 9 & 40 & 2017 \\
\hline
\end{tabular}

CH: carga horária; DE: dedicação exclusiva. MFC: Medicina de Família e Comunidade. Fonte: Elaborado pelas autoras, 2019.

anos, sendo o sexo feminino mais prevalente. Em relação à instituição de ensino, quatro eram docentes da U1 (uma enfermeira, uma fisioterapeuta, uma médica e uma odontóloga) e cinco da U2 (uma filósofa e quatro médicos), percebendo-se que as áreas de formação trazem uma visão multiprofissional ao ensino da disciplina de Saúde Coletiva. Quanto à pósgraduação, há dois doutores e quatro mestres; os demais estão cursando o mestrado. O tempo de docência na instituição atual se situa entre um e nove anos, e a maioria está entre um e dois anos, ou seja, em início de carreira. A faixa salarial dos participantes varia: cinco recebem entre três e seis salários mínimos (SM-2018), três recebem entre seis e nove SM e apenas um recebe mais de nove SM.

Seis participantes têm na docência sua principal ocupação, mas a carga horária dedicada à função varia, havendo apenas um com dedicação exclusiva. A maioria dos professores da U1 tem uma carga horária menor dedicada à docência do que os docentes na U2, na qual dois trabalham 40 horas por semana. Contudo, ainda sentem dificuldade em exercer essa função:

"Então dá mais trabalho, exige tempo e às vezes a pessoa não tem tempo por questões financeiras, porque ela está trabalhando em outras coisas ou não vê motivação [...]" (A1).

Como afirma Mesquita, Meneses et al. ${ }^{15}$, é necessário que o profissional tenha uma reflexão crítica do exercício da docência para a valorização da profissão docente, dos saberes dos professores, do seu trabalho coletivo das instituições como espaços de formação contínua, bem como para o reconhecimento do professor como investigador e produtor de conhecimento. De acordo com os participantes:

Eu acho que ele é um orientador, ele é estimulador [...] (A1).

O nosso papel é de ser um pesquisador a vida inteira, porque passamos a ser mais facilitadores do processo, mas temos que estar sempre muito atualizados, precisamos ter o domínio da metodologia e também do conteúdo, porque para ajudá-los a fazer as perguntas tem que saber o que é o conteúdo-chave para poder orientar [...] (B1).
Referente às demais características sociodemográficas, não foram encontradas diferenças significativas entre os dois grupos.

A seguir, são descritas as categorias de análise que serão examinadas com maior profundidade segundo os objetivos do estudo, explorando as percepções dos docentes ante a prática das MAP.

\section{Conhecimento e vivências das MAP}

Quanto ao perfil do docente brasileiro dos cursos de Medicina, os profissionais muitas vezes exercem a docência sem os conhecimentos pedagógicos necessários ${ }^{6}$, e essa característica se mantém neste estudo, no qual é possível constatar a carência de formação em MAP. Esse cenário condiz com uma prática em que os docentes ministram as aulas conforme suas convicções e repetem modelos vivenciados durante sua formação ${ }^{17}$. Porém, a formação docente não pode se restringir à participação em cursos eventuais, mas precisa abranger, necessariamente, programas de capacitação, supervisão e avaliação que sejam realizados de forma integrada e permanente ${ }^{15}$.

Se eu te disser que eu tenho experiência com metodologias ativas, eu tenho pouca [...] (A2).

Então eu acabo observando o que os outros professores trabalharam, o que eu fui aprendendo, do que eu vou lendo e vou aplicando [...] (A3).

Formação em metodologias ativas eu não tenho. O que eu tenho é uma formação autodidata (B3).

[...] fiz um curso EAD para docentes da instituição em práticas de metodologias ativas, mas fora isso, em metodologia ativa nada (B4).

Um grupo de professores da disciplina enfocada em ambas as universidades relata que sente desconhecimento, incertezas e dificuldades na utilização de metodologias ativas na sua prática docente em saúde: 
[...] Tens que deixar isso o mais dinâmico possível, o mais claro, que seja usando o caso de alguém de uma UBS ou de uma visita que ele foi fazer (A3).

[...] faço exposição dialogada, tem momentos que tem que ter essa parte, também oriento estudo dirigido e depois a gente faz debate, tipo seminário, enfim é bem diverso, às vezes utilizo pequenos vídeos [...] (B1).

Procuramos adotar uma metodologia que consideramos como metodologia ativa [...] os primeiros encontros são encontros presenciais, teóricos, com aulas expositivas, leituras de alguns artigos, materiais, tem alguns vídeos também que a gente traz para as aulas. [...] Então eles vão até as Unidades, voltam, organizam materiais e nós fazemos debate (B3).

$\mathrm{Na}$ sua prática, os professores necessitam pensar sobre o processo educacional com a finalidade de estruturá-lo, de modo a oportunizar reflexões, habilidades e ações. Essa estruturação é resultado do planejamento que está diretamente relacionado à escolha do conteúdo, de atividades, de recursos disponíveis e da metodologia a ser adotada'.

[...] tens que seguir um cronograma, que seguir um conteúdo programático, um plano de ensino, mas sempre com diálogo, por mais que seja uma aula expositiva [...] (A3).

[...] estou tentando colocar, mesclar, aulas tradicionais de exposição, só que sempre fazendo com que eles reflitam e tentando permear essas aulas tradicionais sempre com casos clínicos $[\ldots]$ (B2).

[...] os primeiros encontros são encontros presenciais, teóricos, com aulas expositivas [...] (B3).

Percebe-se no discurso dos participantes, sejam eles médicos ou não, que há intenção de usar DAEA; contudo, isso fica fragmentado e intercalado com aulas expositivas tradicionais, durante as quais ocorre a transmissão de conhecimento, ficando a cargo das novas ferramentas apenas trazer a atenção dos alunos de volta à aula, a fim de deixá-la mais interessante ${ }^{24}$.

Tem o júri simulado, que é outra forma de trazer o SUS. Utilizo também uma metodologia que não sei como chama, aprendi como GVGO [Grupo de Verbalização e Grupo de Observação], mas para estudar, por exemplo, a legislação do SUS, cada grupo estuda uma das leis [...] (B1).

Aqui na medicina a gente usa bastante o TBL [Team-based Learning] a gente usa os pós testes que também são uma forma de fixar conteúdo [...] está sendo bem interessante trabalhar o lúdico, os jogos que dão ideias diferenciadas para utilizar mais metodologias ativas diferentes, porque senão a gente fica sempre nas mesmas [...] (B2).

Uso um pouco de PBL [Problem Based Learning] aqui tenho esses casos clínicos que criei para tematizar a politica [...] (B5).

Percebe-se que os docentes da U1 têm algum conhecimento sobre quais tipos de MAP existem e como utilizá-las. Porém, o currículo ainda é fragmentado, deixando a cargo do docente quais estratégias didáticas utilizar na sua aula. Já na U2 há maior desconhecimento, existindo ainda muita confusão conceitual entre MAP, estratégias didáticas ativas e DAEA, o que vai ao encontro do que Freitas et al. ${ }^{9}$ relataram.

Nas observações realizadas em sala de aula, constatou-se um grande número de alunos por turma, o que por si só dificulta o aprendizado ativo e demonstra que a estruturação curricular não está sustentada nas MAP, já que os processos pedagógicos ativos devem estar preferencialmente organizados em pequenos grupos de seis a oito alunos com um facilitador. Os recursos mais utilizados foram os audiovisuais com projetor e vídeo, realização de seminários, discussão de casos e desenvolvimento de produtos relacionados aos conteúdos da disciplina, mas sobressaem as aulas expositivas, com organização tradicional, em que o docente assume o papel de detentor do conhecimento e o aluno está na posição de ouvinte.

Mesmo com o reconhecimento das tendências pedagógicas que direcionam o processo de ensino-aprendizagem e com algumas tentativas individuais dos docentes de incluir DAEA no decorrer da aula, a influência do método tradicional de ensino, centrado no professor e nos conteúdos, ainda é fortemente verificada no cotidiano dos professores da disciplina de Saúde Coletiva de ambas as universidades. É possível observar que não há estruturação metodológica sustentada nas MAP na disciplina, diferentemente do que está descrito no PPP das duas universidades.

Intervir nesse processo de naturalização profissional exige uma energia sistematizada de reflexão, baseada na desconstrução da experiência. Os sujeitos professores só alteram suas práticas quando são capazes de refletir sobre si e sobre sua formaçã ${ }^{25}$ com o objetivo de deixar a perspectiva do mestre, transmissor de conhecimento, para assumir um papel de facilitador do processo de ensino, pois o professor, nas MAP, assume uma posição muito mais de cooperação do que de detentor da verdade ${ }^{6}$. Seu principal papel é estimular o pensamento crítico e o autoaprendizado dos estudantes.

Possibilidades e dificuldades da prática profissional dos docentes com as MAP

Em relação às possibilidades, os dois grupos de docentes apontam que as MAP são importantes tanto para o docente quanto para o discente:

A potencialidade é de mudar um pouquinho esse modelo de ensino clássico de que o professor tem a razão falando [...] acho que nessa troca pode haver um ganho muito legal de o aluno poder contribuir mais, ter que tomar a iniciativa, é uma forma diferente de aprendizado que ele tem que se mobilizar. Acho que estimula mais a criatividade, a liderança do aluno [...] (A3).

Acho que tem uma potência enorme de fazer os estudantes serem protagonistas, de despertar o desejo, a vontade de estudar. É ser o construtor do seu saber, de estar comprometido, de se encantar, porque o conhecimento é uma coisa que gera muito prazer [...] a busca pela sabedoria é algo que encanta e que dá muito prazer, então se a gente consegue desafiar o estudante a isso, ele se encanta e a gente vê [...] (B1).

Ao abordarem essa percepção, Xavier, Oliveira et al. ${ }^{18}$ afirmam que o papel do professor é facilitar o processo de ensino, estimulando os aprendizes a eleger soluções relevantes para cada situação-problema, já que essas novas formas de trabalhar com o conhecimento no ensino

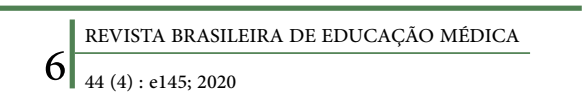


superior procuram romper com o modelo tradicional de ensinar.

De acordo com Freitas et al. ${ }^{9}$, a relação existente entre docente e discente permite a troca de saberes, sendo condição indispensável ao processo ensino-aprendizagem, o que dinamiza o processo educativo e lhe dá sentido. $\mathrm{O}$ professor também experimenta mudanças, pois, ao conhecer e se aproximar mais dos estudantes, pode rever suas ideias e, sobretudo, refletir sobre seus valores e julgamentos. Nessa perspectiva, o docente se torna cada vez mais um gestor e orientador de caminhos coletivos e individuais, previsíveis e imprevisíveis, em uma construção mais aberta, criativa e empreendedora ${ }^{14}$, conforme pode ser observado nos seguintes trechos oriundos de participantes de ambas as universidades:

[...] extremamente gratificante, não consigo me ver longe disso (A4).

[...] a gente se encontra, eles vêm me agradecer por esses pequenos gestos que eu acho que é de um educador cuidador que a gente precisa ter (B1).

[...] a gente também se sente mais realizado como professor. [...] Eu acho que o professor se sente melhor, acho que se sente mais realizado, foi essa impressão hoje quando eu saí da aula (B5).

Contudo, as inovações pedagógicas exigem tempo, esforço e recursos humanos e estruturais. É necessário haver maior carga horária para pensar e realizar as ações exigidas pelas MAP, o esforço é uma condição para atingir as metas estabelecidas na inovação, e às vezes os recursos necessários são escassos ou inexistentes para suprir as exigências que as MAP trazem, como mais professores e maior número de salas de aula para trabalhar em pequenos grupos, aspecto fundamental do processo pedagógico das metodologias ativas. No entanto, embora a falta possa ser um obstáculo à inovação, sua presença também não é garantia de seu alcance ${ }^{16}$.

A falta de tempo do docente para planejamento e preparação das aulas está presente nas falas oriundas de ambas as instituições, pois somente um deles atua em dedicação exclusiva. Segundo Almeida e Batista $^{26}$, a desvalorização do professor, o pouco reconhecimento institucional, os baixos salários e, consequentemente, a falta de tempo por ter que compensar o ganho financeiro com outras atividades muitas vezes comprometem o processo de desenvolvimento docente.

[...] para preparar uma aula expositiva, tu vais levar um tempo para fazer, ela está pronta e tu sempre vais usar a mesma. Uma Metodologia Ativa não é bem assim, tu até podes ter pronto o que vais precisar, mas vai ter que corrigir depois alguma coisa talvez, ou preparar todo um material para aquela turma. [...] Acho que é mais ou menos isso que eu falei, do professor ter tempo para fazer isso (A3).

[...] acho que demanda muito mais tempo de preparação de aula do que uma aula teórica expositiva normal e, às vezes, a gente acaba meio que se acomodando em função de que tem um tempo restrito para formação de aula e não dá, mas existe, acho que essa possibilidade existe (B4).

A este estudo, acrescenta-se a falta de experiência dos professores da disciplina de Saúde Coletiva, pois é possível perceber, a partir dos depoimentos, a ausência de formação para o exercício da docência e a falta de planejamento para exercer essa atividade. Em geral, esses profissionais ingressam na carreira de educadores sem possuir capacitação pedagógica para a atuação docente, apesar da habilidade em sua especialidade ${ }^{18}$ :

[...] quando comecei a dar aulas, comecei com Supervisão de Estágio, [...] então me convidaram para dar aula e eu disse, "mas eu não sei dar aula", "mas é fácil, a gente te ajuda" (A3).

Eu não tinha tido experiência de docência formal anteriormente a esta (B3).

Outra dificuldade trazida pelos profissionais é o papel do aluno no processo ativo de aprendizagem. Gleason et al. ${ }^{8}$ apontam como barreira potencial a falta de interesse de disposição ou de preparo do aluno para participar da aprendizagem ativa, já que palestras tradicionais, com sua transmissão unidirecional de informações, exigem pouco esforço de sua parte. A aprendizagem ativa é um afastamento da modalidade passiva, pois exige que os alunos pensem de forma crítica sobre o processo. Consequentemente, alguns podem resistir ao aprendizado ativo. Isso foi observado em sala de aula, em que os estudantes estavam acomodados com a prática de serem apenas ouvintes e, quando solicitados a contribuir, poucos participaram:

Às vezes tem um pouco de resistência, mas aula pronta é o que eles estão acostumados [...] (A1)

[...] porque o aluno é acostumado a ficar sentado e só recebendo a informação, então tu chegares e quebrar o paradigma [...] (A3).

Então eles querem tudo pronto, mastigado. Se puder ser colocado, introduzido no cérebro deles, parece ser melhor (B3).

[...] a questão de motivar os alunos para participação, que a metodologia ativa demanda participação e se o aluno não está predisposto a colaborar fica um pouco mais complicado [...] (B4).

Essa falta de disponibilidade do aluno em participar em processos ativos de aprendizagem pode acontecer no início do processo, mas possibilitar que ele tenha uma compreensão clara do objetivo dessas atividades e estabelecer papéis e responsabilizações pode melhorar a participação nas aulas e o desempenho dele ${ }^{8}$.

Como afirmam Xavier, Oliveira et al. ${ }^{18}$ sobre a relação docente-discente, os conteúdos abordados no processo de ensino-aprendizagem devem ser dinâmicos e favorecer uma maior aproximação entre professores e alunos, bem como conseguir contribuir para a formação de profissionais críticos e reflexivos. Para tanto, o docente deve envolver o discente em situações diversas. Nesse caso, o professor dever abordar o conhecimento prévio, diversificar os cenários e valorizar a prática para facilitar a construção de novos conhecimentos ${ }^{18}$. Além disso, as MAP promovem as condições necessárias para atividades que estimulem o desenvolvimento de diferentes habilidades de pensamento dos alunos e possibilitem ao professor atuar naquelas situações que promovam a autonomia, substituindo, sempre que possível, as situações evidentemente controladoras ${ }^{9}$.

Não existem facilidades para os professores que se lançam nesse desafio pedagógico ${ }^{15}$, já que a utilização de métodos ativos exige maior envolvimento/ conhecimento do processo de ensino-aprendizagem, imprevisibilidade e variabilidade, por serem centrados no aluno, flexibilidade, compartilhamento

REVISTA BRASILEIRA DE EDUCAÇÃO MÉDICA

7 44 (4) : e145; 2020 
de poder e construção conjunta do conhecimento ${ }^{16,26}$.

Esses aspectos nos levam a pensar em como melhorar esse processo. Os docentes sugerem a realização de cursos de formação com o objetivo de qualificá-los para atividades coerentes com os métodos ativos de aprendizagem. Também destacam a formação em pequenos grupos, seguindo as metodologias ativas, em consonância com o estudo de Xavier, Oliveira et al. ${ }^{18}$. Contudo, quando se compararam as duas universidades, verificou-se que a U1 promove cursos de formação pontuais, com abordagens apenas teóricas das diversas metodologias ativas existentes, sem relacioná-las com as vivências e práticas dos docentes. Na U2 os momentos de formação são muito esporádicos, sem o propósito de capacitar o docente para sua prática diária.

[...] capacitar os professores da Saúde Coletiva nessa questão das metodologias ativas (B2).

Principalmente de promover, promover a educação continuada para o docente [...] (B4).

Essa prática corrobora as afirmações de Mesquita, Meneses et al. ${ }^{15}$, pois a formação continuada deveria ser ofertada indicando que é necessário realizar momentos formativos para todos os envolvidos no processo educativo. O objetivo é formar um profissional ativo e preparado para o exercício da docência, principalmente com o intuito de suprir as necessidades de compreensão de pedagogias, da metodologia e dos métodos que favorecem uma aprendizagem mais crítica, reflexiva e articulada com a realidade. Contudo, quando se pensa em educação continuada, o olhar volta-se para a instituição e para o apoio dela a esse processo:

[...] temos algumas formações para professores aqui na Faculdade de Medicina que eu acho que foi um avanço muito grande (A1).

[...] não vai ressignificar a prática dela numa tarde de capacitação, então a gente está falando na verdade de uma Política de Educação Permanente na universidade, nas instituições, para fazer com que numa capacitação que tivesse seis meses pudesse aprender algo e aplicar isso (B5).

É fundamental que as instituições propiciem aos docentes as condições necessárias para que eles repensem e modifiquem a prática educativa, considerando a imprescindibilidade de formar professores capazes de transformar os alunos em sujeitos críticos, reflexivos e questionadores, em resposta às demandas da sociedade ${ }^{15}$.

O desenvolvimento de práticas de formação/desenvolvimento docente em saúde deve estar inserido em um projeto institucional mais amplo, o que implica assumi-lo como um processo permanente ${ }^{26}$. Quando se analisaram os relatos dos docentes, observou-se que nenhuma das duas instituições promove essa formação, disponibilizando a seus docentes apenas capacitações pontuais, sem estimular espaços para reflexão em conjunto sobre práticas pedagógicas instituídas, nem para reformulá-las, muito menos para compartilhamento de experiências.

Concordando com Almeida e Batista ${ }^{26}$ de que a gestão das escolas médicas deve ser de lideranças capazes de planejar e gerenciar o currículo, e garantir que as atividades docentes e discentes sejam cumpridas com motivação e que os resultados esperados sejam alcançados, o trecho a seguir considera o seguinte:
[...] fazendo as capacitações e acho que eles têm que mobilizar mesmo o corpo docente, dar condição de capacitar o pessoal, mostrar as possibilidades tanto de recurso estrutural, físico, quanto recurso humano para dar um suporte nessas metodologias e também tem toda a questão gerencial também de colocar algumas coisas na questão do Plano Político Pedagógico, Plano de Ensino (A3).

\section{CONSIDERAÇÕES FINAIS}

A formação atual do profissional médico preconizada pelas DCN-CGM demanda das instituições de ensino superior mudanças curriculares e processos pedagógicos sustentados nas MAP. Em ambos os cursos estudados, os PPPs propõem formar um médico que desenvolva o pensamento crítico e reflexivo e "com capacidade para atuar nos diferentes níveis de atenção à saúde, com ações de promoção, prevenção, recuperação e reabilitação da saúde, nos âmbitos individual e coletivo" ${ }^{\text {"1, }}$. Contudo, foi observada uma contradição entre o que está proposto nos PPPs e o que acontece no cotidiano dos cursos de Medicina estudados. Com isso, observa-se um desencontro com as DCN-CGM:

O Curso de Graduação em Medicina terá projeto pedagógico centrado no aluno como sujeito da aprendizagem e apoiado no professor como facilitador e mediador do processo, com vistas à formação integral e adequada do estudante, articulando ensino, pesquisa e extensão, [...] utilizar metodologias que privilegiem a participação ativa do aluno na construção do conhecimento e na integração entre os conteúdos ${ }^{1,11}$.

Pode-se observar que as mudanças das diretrizes propõem modificações nas características dos docentes e no desenvolvimento de suas práticas pedagógicas. Todavia, muitos docentes não têm experiência com as MAP e não sabem como poderiam utilizá-las na sua prática pedagógica diária. Acabam, assim, por utilizar processos mistos, com DAEA e ensino tradicional, o que culmina em dificuldades na sua inserção no processo pedagógico. Todos os professores relatam o importante papel das MAP na formação do discente, mas alegam que ainda precisam se preparar para colocá-las em prática.

Dessa forma, as propostas de desenvolvimento docente ancoradas na educação permanente contribuirão para embasar os docentes em suas necessidades e dificuldades referentes à formação em MAP, assim como será oferecido um momento de troca de experiências sobre suas práticas diárias.

Existe uma preocupação referente ao tipo de profissional médico que está sendo formado e ao devido atendimento das DCN-CGM. Está comprovado que as MAP são essenciais na formação desses profissionais, principalmente porque estimulam os alunos a ter um posicionamento crítico reflexivo e aprender com as práticas. Além disso, elas consideram todos os conhecimentos prévios dos discentes e os incentivam a sair da faculdade com competência de aprender a aprender.

Quando se analisou o PPP de cada uma das universidades estudadas, observou-se uma discrepância entre o conteúdo dele e o que propõem as DCN-CGM, pois os currículos de ambas as instituições ainda são fragmentados - a U1 utiliza o método tradicional, dividido em disciplinas, enquanto a U2 tem uma organização modular.

O PPP das duas universidades menciona as MAP, mas, com a prática

\footnotetext{
\begin{tabular}{l|l}
\hline \multirow{8}{*}{8} & REVISTA BRASILEIRA DE EDUCAÇÃO MÉDICA \\
\hline 44 (4) : e145; 2020
\end{tabular}
} 
vivenciada e observada dos docentes, pode-se concluir que as aulas assumiram um formato expositivo e com um referencial pedagógico predominantemente tradicional. Como há um desencontro entre o que está registrado no PPP e a sala de aula, cabe ao docente a decisão de qual tipo de metodologia irá empregar nos seus encontros pedagógicos, já que o currículo instituído nas duas faculdades não está estruturado concretamente nas MAP, mas sim em uma pedagogia tradicional que permite a utilização de DAEA. Percebe-se que a coordenação dos cursos apoia e incentiva as MAP, mas não as coloca como metodologia principal da formação do discente. Também foi observado que o PPP da U2 é mais integrado, mas, em termos de formação do docente e prática pedagógica, é mais tradicional, ao contrário da U1 que apresenta um currículo tradicional em disciplinas e docentes com uma prática mais ativa e com estímulo e apoio institucional mais abrangentes. Essa contradição entre teoria (PPP) e prática (currículo tradicional, processo pedagógico, formação dos docentes e do estudante de Medicina) dificulta e tenciona a prática pedagógica do professor e a formação do futuro médico, conforme preconizam as DCN-CGM.

Assim, além da formação docente, há outras ações institucionais que podem ser exploradas na adoção de MAP, principalmente aquelas voltadas à reestruturação do PPP e à colaboração contínua para oferecer meios aos docentes de aplicar as MAP em suas aulas.

Observa-se que ainda é necessário ampliar a discussão acerca do tema, sobretudo no que se refere ao papel da gestão e à formação pedagógica necessária para a efetividade da docência em saúde baseada nas MAP, as quais, mesmo com todas as diretrizes norteadoras e reestruturadoras desse ensino, não garantem que a formação ocorra conforme o preconizado.

Dessa forma, é preciso estimular as universidades a ter um projeto de educação permanente com definição de qual referencial teórico assumirão, em que as MAP sejam colocadas como ponto principal na prática docente, de modo que o modelo de formação e o PPP instituídos possam ser repensados.

\section{AGRADECIMENTO}

As autoras agradecem ao Programa de Pós-Graduação em Avaliação de Tecnologias para o SUS do Grupo Hospitalar Conceição (GHC) o apoio em todas etapas do desenvolvimento da pesquisa, desde a idealização do projeto até a publicação do artigo nesta revista.

\section{REFERÊNCIAS}

1. Brasil. Resolução CNE/CES $n^{\circ}$ 3/2014. Institui as Diretrizes Curriculares Nacionais do Curso de Graduação em Medicina e dá outras providências. Diário Oficial da União, Brasília, DF; 23 jun 2014; Seção 1, p. 8-11.

2. Nespoli G. Os domínios da tecnologia educacional no campo da saúde. Interface Comum Saúde Educ. 2013;17(47):873-44.

3. Almeida MJ, Campos JJB, Turín B, Nicoletto SCS, Pereira LA, Rezende, LR, et al. Implantação das Diretrizes Curriculares Nacionais na Graduação em Medicina no Paraná. Rev Bras Educ Med. 2007;31(2):156-65.

4. Cotta RMM. Descentralização das políticas públicas de saúde: do imaginário ao real. Viçosa: UFV; 1998.

5. Batista NA, Vilela RQB, Batista SHSS. Educação médica no Brasil. São Paulo: Cortez; 2015.
6. Machado CDB, Wuo A, Heinzle M. Educação médica no Brasil: uma análise histórica sobre a formação acadêmica e pedagógica. Rev Bras Educ Med. 2018;42(4):66-73.

7. Farias PAM, Martini ALAR, Cristo CS. Aprendizagem ativa na educação em saúde: percurso histórico e aplicações. Rev Bras Educ Med. 2015;39(1):143-58.

8. Gleason BL, Peeters MJ, Resman-Targoff BH, Karr S, McBane S, Kelley $\mathrm{K}$, et al. An active-learning strategies primer for achieving abilitybased educational outcomes. Am J Pharm Educ. 2011;75(9):186.

9. Freitas DA, Santos EMF, Lima LVS, Miranda LN, Vasconcelos EL, Nagliate PC. Saberes docentes sobre processo ensino-aprendizagem e sua importância para a formação profissional em saúde. Interface (Botucatu). 2016;20(57):437-48.

10. Machado MMBC, Sampaio CA, Macedo SM, Figueiredo MFS, Rodrigues Neto JF, Lopes IG, et al. Reflexões e significados sobre competências docentes no ensino médico. Avaliação. 2017; 22(1):85-104.

11. Conceição CV, Moraes MAG. Aprendizagem cooperativa e a formação do médico inserido em metodologias ativas: um olhar de estudantes e docentes. Rev Bras Educ Med. 2018; 42(4):115-22.

12. Gomes AP, Rego S. Transformação da educação médica: é possível formar um novo médico a partir de mudanças no método de ensinoaprendizagem? Rev Bras Educ Med. 2011;35(4):557-66.

13. Maia JA. Metodologias problematizadoras em currículos de graduação médica. Rev Bras Educ Med. 2014;38(4):566-74.

14. Moran J. Mudando a educação com metodologias ativas. In: Souza CA, Morales OET, organizadores. Convergências midiáticas, educação e cidadania: aproximações jovens. Ponta Grossa: Proex/UEPG, 2015.

15. Mesquita SKC, Meneses RMV, Ramos DKR. Metodologias ativas de ensino/aprendizagem: dificuldades de docentes de um curso de enfermagem. Trab Educ Saúde. 2016;14(2):473-86.

16. Jerez O, Silva C, Hasbún B, Cevallos MR. Innovando en educación superior: experiencias clave en Latinoamérica y el Caribe 2016-2017. Santiago: Facultad de Economía y Negocios, Universidad de Chile; 2017.

17. Tsuji H, Silva RHA. Aprender e ensinar na escola vestida de branco: do modelo biomédico ao humanístico. São Paulo: Phorte; 2010.

18. Xavier LN, Oliveira GL, Gomes AA, Machado MFAS, Eloia SMC. Analisando as metodologias ativas na formação dos profissionais de saúde: uma revisão integrativa. Sanare. 2014;13(1):76-83.

19. Universidade Federal da Fronteira Sul. Projeto Pedagógico do Curso de Graduação em Medicina. Passo Fundo, RS; maio 2013.

20. Universidade de Passo Fundo. Projeto Pedagógico do Curso de Medicina: atualização Medicina Integral 5236. Passo Fundo, RS; 2017. [Documento interno].

21. Yin RK. Estudo de caso: planejamento e métodos. 3a ed. Porto Alegre: Bookman, 2005.

22. Minayo MCS. Amostragem e saturação em pesquisa qualitativa: consensos e controvérsias. Rev Pesq Qual Abr. 2017;5(7):1-12.

23. Brasil. Resolução $\mathrm{n}^{\circ} 466$, de 12 de dezembro de 2012. Aprova as diretrizes e normas regulamentadoras de pesquisas envolvendo seres humanos. Brasília, DF; 12 dez 2012.

24. Marin MJS, Lima EFG, Paviotti AB, Matsuyama DT, Silva LKD, Gonzalez C, et al. Aspectos das fortalezas e fragilidades no uso das metodologias ativas de aprendizagem. Rev Bras Educ Med. 2010;34(1):13-20.

REVISTA BRASILEIRA DE EDUCAÇÃO MÉDICA

9 $94(4):$ el45; 2020 
25. Cunha MI. Docência na universidade, cultura e avaliação institucional: saberes silenciados em questão. Rev Bras Educ. 2006;11(32):258-71.

26. Almeida MTC, Batista NA. Ser docente em métodos ativos de ensino-aprendizagem na formação do médico. Rev Bras Educ Med. 2011;35(4):468-76.

\section{CONTRIBUICÃ̃O DAS AUTORAS}

Maríndia Biffi foi a idealizadora do estudo e dos conteúdos teóricos, participou da redação e revisão do texto. Margarita Silva Diercks e Ananyr Porto Fajardo contribuíram na orientação e coorientação dos trabalhos e na revisão do texto. Bárbara Cristina contribuiu na revisado do texto.

\section{CONFLITO DE INTERESSES}

As autoras declaram não haver conflito de interesses neste estudo.

\section{ENDEREÇO PARA CORRESPONDÊNCIA}

Maríndia Biffi. Avenida Presidente Vargas, 655, ap. 504, Marau, RS, Brasil. CEP: 99150-000.

E-mail: marindiabiffi@hotmail.com

\section{ERRATA}

Na página 1 ,

Onde se lia:

"Bárbara Cristina"

leia-se:

"Bárbara Cristina Barreiros"

Revista Brasileira de Educação Médica 44 (4): e145, 2020. 